\title{
Ionic-Liquid-Based Bioisoprene Recovery Process Design
}

\section{Chen, Yuqiu; Liu, Xinyan; Kontogeorgis, Georgios M.; Woodley, John M.}

\section{Published in:}

Industrial and Engineering Chemistry Research

Link to article, DOI:

10.1021/acs.iecr.0c00146

Publication date:

2020

Document Version

Publisher's PDF, also known as Version of record

Link back to DTU Orbit

Citation (APA):

Chen, Y., Liu, X., Kontogeorgis, G. M., \& Woodley, J. M. (2020). lonic-Liquid-Based Bioisoprene Recovery Process Design. Industrial and Engineering Chemistry Research, 59(16), 7355-7366.

https://doi.org/10.1021/acs.iecr.0c00146

\section{General rights}

Copyright and moral rights for the publications made accessible in the public portal are retained by the authors and/or other copyright owners and it is a condition of accessing publications that users recognise and abide by the legal requirements associated with these rights.

- Users may download and print one copy of any publication from the public portal for the purpose of private study or research.

- You may not further distribute the material or use it for any profit-making activity or commercial gain

- You may freely distribute the URL identifying the publication in the public portal

If you believe that this document breaches copyright please contact us providing details, and we will remove access to the work immediately and investigate your claim. 


\title{
Ionic-Liquid-Based Bioisoprene Recovery Process Design
}

\author{
Yuqiu Chen, Xinyan Liu, Georgios M. Kontogeorgis, and John M. Woodley* \\ Cite This: https://dx.doi.org/10.1021/acs.iecr.0c00146 \\ Read Online
}

ACCESS |

Lلll Metrics \& More

Article Recommendations

Supporting Information

ABSTRACT: Bioisoprene, which can be produced from renewable feedstocks through fermentation, is a promising alternative to petroleum-derived isoprene. However, challenges including the selection of feasible recovery techniques for bioisoprene should be addressed to achieve economic and technical competitiveness. In this work, ionic liquids (ILs) are first introduced as solvents for the recovery of bioisoprene. To describe the thermodynamic behavior, the UNIFAC-IL model is first extended to the bioisoprene systems as it combines gas-organic chemicals in IL-containing systems. Using a computer-aided IL design (CAILD) method, six out of 248742 structurally constrained ILs are screened as optimal candidates for their further performance evaluation. Simulation results indicate that all six ILs have much better process performance than that of the alternative, isopropyl myrisate. Moreover, $\left[\mathrm{N}_{1,1,3,0}\right][\mathrm{DMP}]$ is identified as the best IL with the lowest solvent flow rate and the highest recovery ratio of isoprene. This work shows the potential of using ILs for the recovery of bioisoprene from fermentation off-gas.

\section{INTRODUCTION}

Isoprene (2-methyl-1,3-butadiene) is an important commodity chemical for producing a wide variety of industrial products including cis-polyisoprene or synthetic rubber used in tires, as well as elastomers used in surgical gloves, motor mounts, fittings, rubber bands, and shoes. Isoprene was first produced synthetically in 1860 by the pyrolysis of natural rubber. ${ }^{1}$ Since the 1970s, most isoprene production on an industrial scale comes from petrochemical resources and was first commercialized by a company now known as Nippon Zeon (Tokyo, Japan). ${ }^{2}$ In the process of petroleum steam cracking, isoprene can be selectively and efficiently extracted from complex mixtures of hydrocarbons by extractive distillation using polar organic solvents. ${ }^{3}$ Therefore, on a large scale, isoprene with a competitive price can be produced from fossil feedstocks. Nonetheless, the current supply and demand balance, as well as the demand for processes based on sustainable feedstocks within the global isoprene industry, is at risk in the coming years. Furthermore, isoprene supply is further limited as availability of crude $\mathrm{C} 5$ feed streams for isoprene extraction is declining since the trend of using light hydrocarbons or natural gas as a feedstock in the refining industry. ${ }^{1}$

With a growing industrial demand for isoprene and a simultaneous environmental imperative to reduce greenhouse gases, bioisoprene produced from renewable sources (e.g., glucose, sucrose) through fermentation is being considered as a potential alternative to petroleum-derived isoprene. To improve the yield of diene products, Abdelrahman and coworkers proposed a hybrid process of combining fermentation

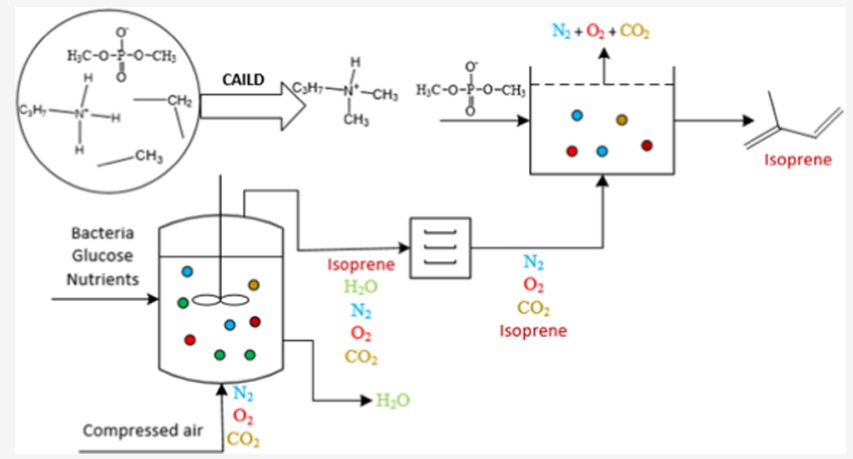

and thermochemical catalysis for reviewable isoprene production. ${ }^{4}$ A most recent work shows that fermentation via mesaconic acid is also possible but provides a few extra benefits over the Escherichia coli process. ${ }^{5}$ Compared to the isoprene production from petrochemical resources, the biological process is more sustainable and environmentally friendly. Nevertheless, the costs of bioisoprene are slightly higher than the actual market price of its fossil counterparts and its global contribution is still small. The results obtained by Morais and co-workers reveal that the isoprene production by bacteria is able to substitute the petroleum-based process, with reasonable energy and material efficiency, but improvements are still required. ${ }^{6}$ Current state-of-the-art technology has led to improved sugar conversion in the fermentation process of isoprene, and since the product has a boiling point of $34{ }^{\circ} \mathrm{C}$, it can be recovered from the fermentation off-gas in a continuous process. ${ }^{1}$ Nonetheless, an advanced bioprocess that is capable of lowering the unit cost of bioisoprene is essential for its further commercial production.

The fermentation process to produce bioisoprene is aerobic and oxygen is continuously supplied by air, while the generated isoprene is released into the vapor phase (off-gas) together

Received: January 8, 2020

Revised: March 5, 2020

Accepted: April 1, 2020 
with water vapor, residual air gases (i.e., $\mathrm{N}_{2}, \mathrm{O}_{2}$ ), and produced gas (i.e., $\mathrm{CO}_{2}$ ). This is unusual for fermentation processes since the product usually resides in the liquid water phase. In principle, when the product is found in the vapor phase, it leads to a particularly attractive downstream process (as the product is separated from liquid byproducts, water, and cells merely by phase separation). However, the concentration of bioisoprene (vapor phase) in the off-gas is very low under aerobic conditions, while the concentration of isoprene (liquid phase) from the petrochemical source for extractive distillation is $10-20 \%{ }^{2}$ Therefore, the recovery efficiency of bioisoprene from off-gas in the downstream process is essential for its replacement of petroleum-derived isoprene.

Various methods ${ }^{7,8}$ have been proposed for the recovery of bioisoprene from off-gas, and among them, separation techniques of activated carbon absorption and solvent extraction have been mainly studied. Mcauliffe's work shows that $>80 \%$ bioisoprene can be recovered from the off-gas using an activated carbon absorption method, ${ }^{9}$ and its separation performance is also verified in Zou's work. ${ }^{2}$ This method is attractive to recover bioisoprene with low concentration at the laboratory level; however, its application in large-scale isoprene recovery is still limited. ${ }^{2}$ For the recovery technique of solvent extraction, unlike the polar solvents such as acetonitrile, $\mathrm{N}$ methylpyrrolidone, and dimethylformamide used in the extraction process of isoprene from petrochemical feed streams, isopropyl myristate and isoparaffin are suggested for the recovery process of bioisoprene since both of them can extract isoprene efficiently from the off-gas. Recent work shows that the mixture of methyl carbitol and sulfolane is also capable of extracting isoprene. ${ }^{2}$

As most separation processes, the problem of solvents' escape into the atmosphere because of their high volatilities and the high energy requirements for their regeneration is also encountered in bioisoprene recovery using conventional organic chemicals as solvents. On the other hand, ionic liquids (ILs) that are completely composed of ions are being considered as potential alternatives for organic solvents in many separation processes (e.g., $\mathrm{CO}_{2}$ capture, azeotropic separation) since they present some attractive features including nonvolatility, low melting point, and high thermal and chemical stability. ${ }^{10}$ To date, the cost of ILs is one of the main limitations to their utilization. The current expense of an IL is suggested as $30 \$ / \mathrm{kg}$ by BASF from IL bulk production, ${ }^{11}$ while the market price of a benchmark organic solvent (i.e., isopropyl myristate) is $2-3 \$ / \mathrm{kg}$. However, the cost of ILs is decreasing with the development of cost-effective synthetic methods and the application of inexpensive raw materials. ${ }^{12,13}$ As reported, large-scale production of triethylammonium hydrogen sulfate $\left(\left[\mathrm{HNEt}_{3}\right]\left[\mathrm{HSO}_{4}\right]\right)$ will reduce the cost as low as $1.24 \$ / \mathrm{kg}$, ${ }^{14}$ which shows that ILs have the potential to compete with conventional organic chemicals in terms of solvent cost.

In biotechnology, the application of ILs has been studied in various fields, ranging from solvents for extraction to reaction media for biotransformation. ${ }^{15-21}$ Additionally, the toxicity mechanism of ILs has been investigated for their environmental and health concerns, ${ }^{22-26}$ and newly synthesized ILs completely derived from nature are being emerged since they are inexpensive, biocompatible, and biodegradable with low toxicity. ${ }^{13}$ Although the use of ILs offers unexpected opportunities in biotechnology, investigations regarding their application in the process of bioisoprene production have never been reported so far. This work aims to investigate the possibility of using ILs for the recovery of isoprene from fermentation off-gas. Considering different ILs generally presenting very distinct properties and separation performances, the selection of suitable ILs is essential for the bioisoprene recovery as well as other IL-based processes. Both experimental and nonexperimental IL screening methods have been proposed and applied in various studies. When sufficient experimental data are available, the experimental based screening method is attractive since it can provide more reliable results. Due to a lack of sufficient experimental data of ILs for the bioisoprene system, a non-experimental-dependent IL screening/design method, i.e., a computer-aided ionic liquid design (CAILD) method, ${ }^{27}$ is considered in this work. In CAILD, UNIFAC-IL models ${ }^{28,29}$ are used for the thermodynamic calculations and group contribution-based methods are used for the prediction of physical properties such as melting point temperature and viscosity. To describe the thermodynamic behavior of the bioisoprene systems involving ILs, the UNIFAC-IL model is extended using a wide range of experimental data from published works and a certain number of pseudo-experimental data from COSMO-RS calculations $^{30-32}$ (Section 2). To evaluate the process performance of the selected IL candidates, process simulation is performed before their further experimental verification. Meanwhile, the isoprene separation process using isopropyl myristate is also simulated and compared. The simulation studies are presented in Section 4, followed by our conclusions.

\section{IL SCREENING}

Under aerobic fermentation conditions, bioisoprene is produced as a vapor-phase product released into the off-gas together with normal air components (e.g., $\mathrm{N}_{2}, \mathrm{CO}_{2}, \mathrm{O}_{2}$ ) and water vapor. Generally, water is removed using a dehumidifier unit before the further separation and recovery of isoprene. Therefore, the selected solvents should be able to extract bioisoprene efficiently and selectively from the air components remained in the fermentation off-gas. To find suitable ILs for this bioseparation task, the design method of CAILD is considered. As the successful application of CAILD largely depends on the availability and reliability of the property prediction methods, group contribution-based physical property prediction models and thermodynamic calculation models such as UNIFAC-IL and COSMO-RS are considered in this work

2.1. Extension of the UNIFAC-IL Model. So far, UNIFAC has been extended to many IL-containing systems and some UNIFAC-based models have also been developed. Among these models, UNIFAC-Lei ${ }^{29,33,34}$ has been widely used in various systems by many authors and COSMOUNIFAC $^{35,36}$ that combines the a priori COSMO-SAC model with the original UNIFAC model has a strong predictive power for fluid-phase equilibria. However, both models treat the cation and the anion as a whole group, which may limit the design space and the flexibility of the CAILD problem. In this work, therefore, the UNIFAC-IL model $^{37}$ that treats all substituent groups, cations, and anions as separate groups is considered. In its current version, the UNIFAC-IL model does not consider components such as $\mathrm{N}_{2}$, and $\mathrm{O}_{2}$ that are involved in the bioisoprene system production and therefore an extension of this model is required for this application. As for most model development studies with UNIFAC-IL, ${ }^{33,37-43}$ the original UNIFAC method ${ }^{44}$ (see eqs A1-AAA12 in 
Table 1. Group's Information about $R_{k}$ and $Q_{k}$ for the Extension of the UNIFAC-IL Model

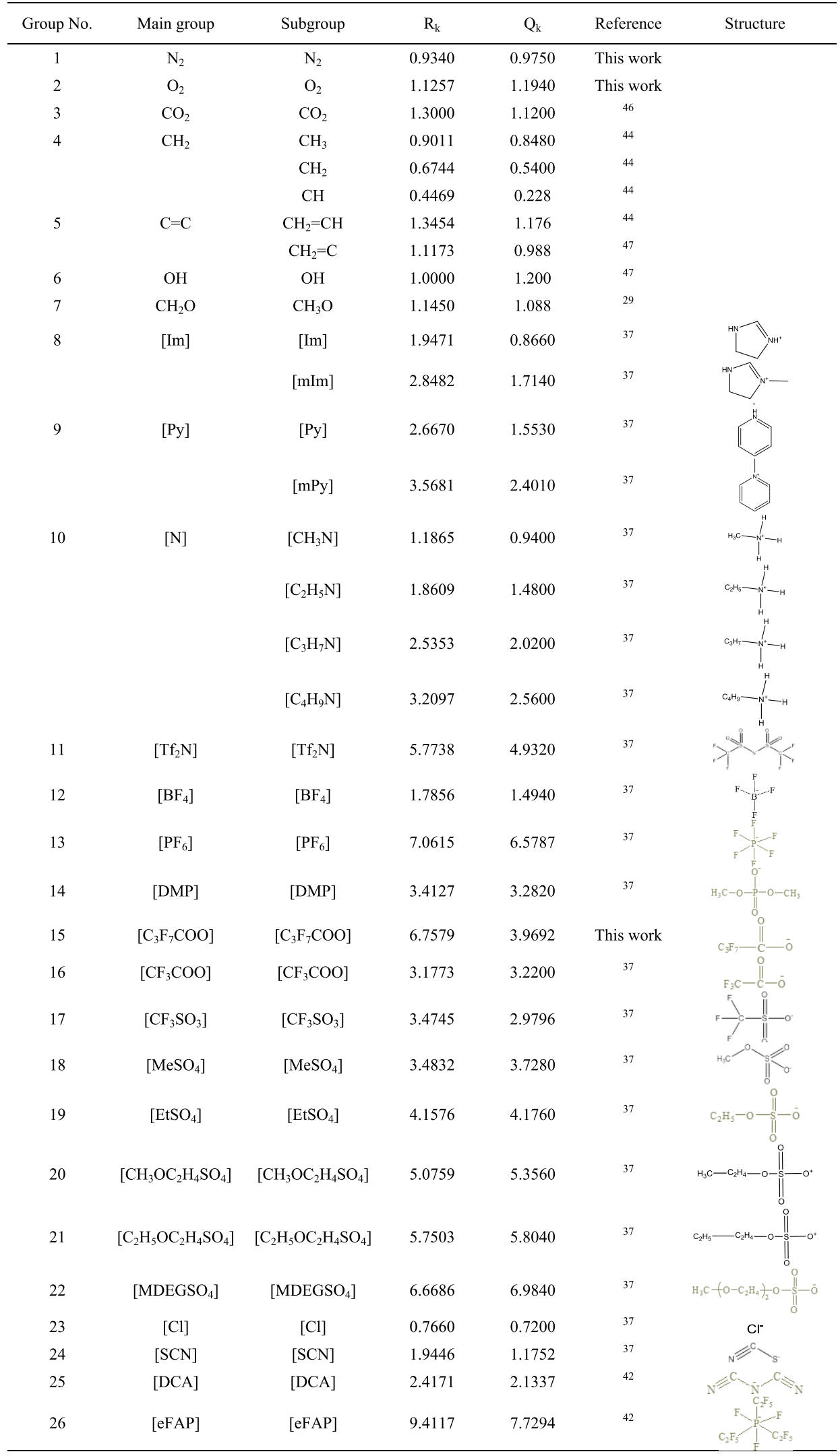

Appendix A) is applied for this extension. To extend the UNIFAC-IL model, the IL molecules should be decomposed properly into separate functional groups, and their dimension- less van der Waals volumes and areas, $R_{k}$ and $Q_{k}$, can be estimated, respectively, by the rules of Bondi as eqs 1 and $2^{45-47}$ 


$$
\begin{aligned}
R_{k} & =\frac{V_{k} \times N_{\mathrm{A}}}{V_{\mathrm{VW}}} \\
Q_{k} & =\frac{A_{k} \times N_{\mathrm{A}}}{A_{\mathrm{VW}}}
\end{aligned}
$$

where $V_{k}$ and $A_{k}$ denote, respectively, the van der Waals group volumes and surface areas of group $k$, which can be calculated from correlations with molecular volumes and surface areas or from quantum chemical calculations. $N_{\mathrm{A}}$ is the Avogadro's number with a value of $6.023 \times 10^{23} / \mathrm{mol}$, and $V_{\mathrm{VW}}$ and $A_{\mathrm{VW}}$ are the standard segment volume and surface area (of the ethylene group in polyethylene) with the values of $15.17 \mathrm{~cm}^{3} /$ mol and $2.5 \times 10^{9} \mathrm{~cm}^{2} / \mathrm{mol}$, respectively. In this work, most of the $R_{k}$ and $Q_{k}$ values for the involved functional subgroups are taken from the published works and the parameters of the remaining subgroups are calculated from COSMO-RS, as shown in Table 1.

So far, there are three main decomposition methods for IL molecules: (1) division into one cation-based group and one anion group; (2) division into several substituent groups with the cation and anion treated as a whole group; (3) all substituent groups, cations, and anions are treated as separate groups. As mentioned above, the third decomposition method is used as it can significantly increase the number of cationanion combinations and consequently enlarge the design space and the flexibility of the CAILD problem. ${ }^{15,42,48}$ Numerous experimental data at a range of temperature of 283.15-384.15 $\mathrm{K}$ and pressure of $0.05-973$ bar $^{49-66}$ are collected for the regression of $\alpha_{n m}$ and $\alpha_{m n}$ by minimizing the average absolute relative deviation (AARD, \%) between experimental and calculated activity coefficients, as shown in eq 3 . In this regression, additional generated pseudo-experimental data at a range of temperature of 298.15-343.15 $\mathrm{K}$ and 1 bar from the COSMO-RS model are also included due to the insufficient experimental data available for some IL group-gas systems.

$$
\mathrm{OF}=\mathrm{AARD}=\frac{1}{N} \sum_{1}^{N}\left|\frac{\gamma_{i}^{\exp }-\gamma_{i}^{\text {calc }}}{\gamma_{i}^{\exp }}\right| \times 100 \%
$$

where $\gamma_{i}^{\exp }$ and $\gamma_{i}^{\text {calc }}$ are the activity coefficients of molecule $i$ from experimental and UNIFAC calculation values, respectively. $N$ represents the total number of regressed data points.

As presented in Table 1 , three gases $\left(\mathrm{N}_{2}, \mathrm{O}_{2}, \mathrm{CO}_{2}\right)$, four conventional main groups, and $20 \mathrm{IL}$ main ionic groups are involved in this UNIFAC-IL model extension. In this regression, the AARD (\%) values between experimental and calculated activity coefficients of $\mathrm{N}_{2}, \mathrm{O}_{2}$, and $\mathrm{CO}_{2}$ are 10.2, 9.2, and $12.1 \%$, respectively, showing the reliability of this extended UNIFAC-IL model. The detailed information about experimental and calculation data can be found in the Supporting Information. Comparisons between the experimental and calculated activity coefficients are presented in Figure 1. The current extended UNIFAC-IL interaction parameter matrix is given in Figure 2. Comparisons of some experimental data that are not used in the regression and their corresponding predicted values from the extended UNIFAC-IL model, as presented in Figure 3, illustrate the good predictive performance of this extended model. Group interaction parameters in the extended UNIFAC-IL model are given in Appendix B.

2.2. Computer-Aided Optimal IL Design. To find attractive ILs using CAILD as a screening method, reasonable constraints and the design objective should be properly set for

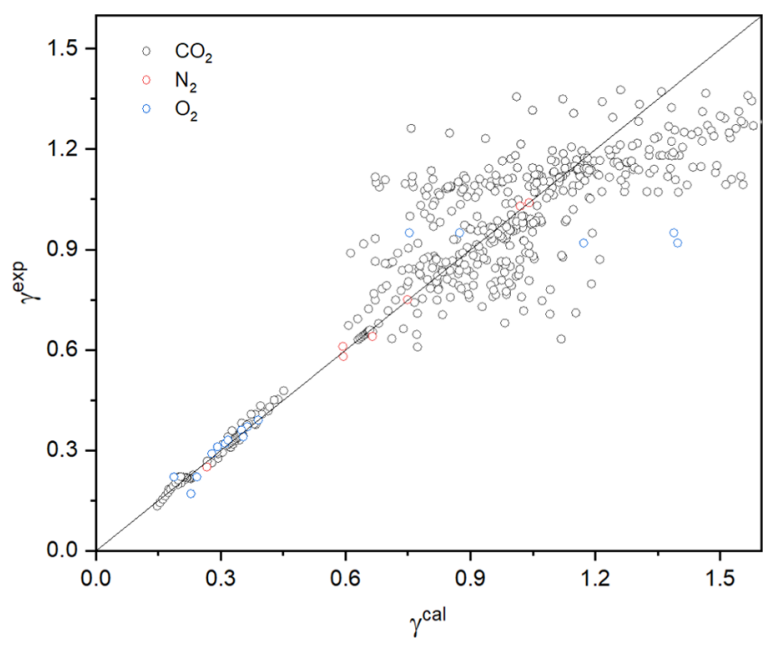

Figure 1. Comparison between experimental and calculated activity coefficients of $\mathrm{N}_{2}, \mathrm{O}_{2}$, and $\mathrm{CO}_{2}$ using the extended UNIFAC-IL model.

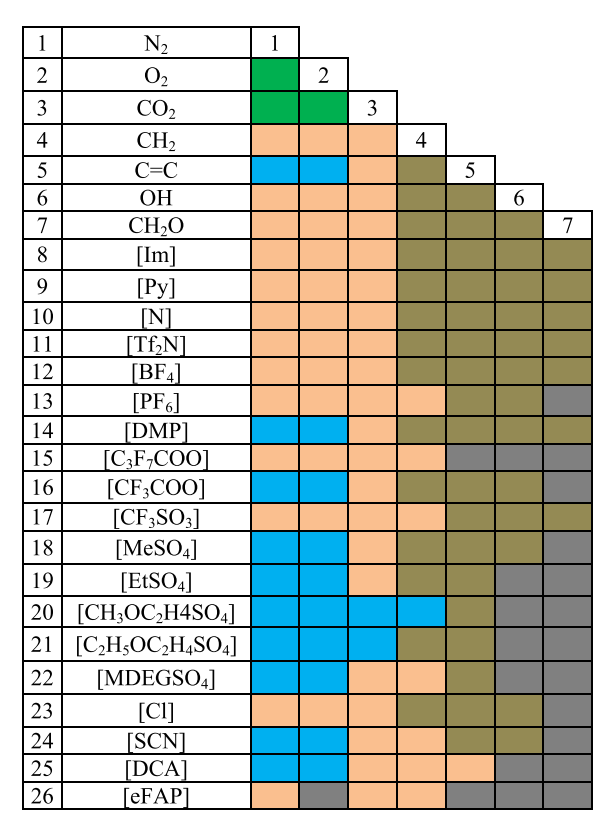

Default parameters [32]

Parameters reported from literature [29, 33]

New parameters by fitting experimental data

New parameters by fitting pseudo-experimental data (calculated from COSMO-RS)

Paramters not available

Figure 2. Current extended UNIFAC-IL interaction parameter matrix.

its corresponding optimization problem. For example, to avoid the solidification of ILs, their viscosities should be relatively low (e.g., less than $50 \mathrm{cP}$ ), considering its significant impact on the practical process operations, and their melting point temperatures must be at least $5 \mathrm{~K}$ less than the temperature at every point in the whole process.

To select suitable solvents for gas separation, both the solubility and selectivity of the targeted component(s) are generally considered in the design stage of solvents. Generally, normal air component gases (e.g., $\mathrm{N}_{2}, \mathrm{O}_{2}$ ) in the bioisoprene system have very low solubility in ILs under atmospheric 


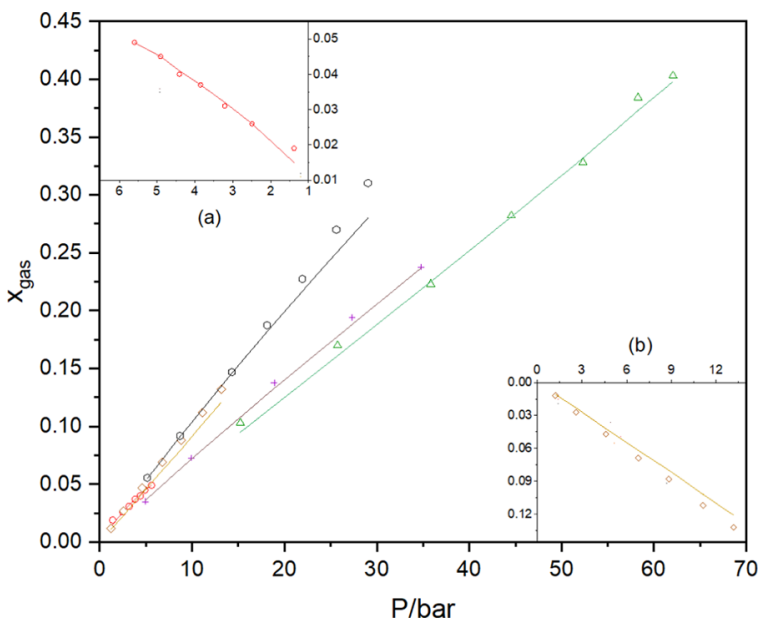

Figure 3. Comparisons of experimental data ${ }^{49,62,67,68}$ and predicted values for $x_{\text {gas }}-P$ covering $\left[\mathrm{CH}_{3} \mathrm{OC}_{2} \mathrm{mIm}\right]\left[\mathrm{Tf}_{2} \mathrm{~N}\right]-\mathrm{N}_{2}$ at $303.15 \mathrm{~K}(\mathrm{O})$ in $(\mathrm{a}),[\mathrm{emIm}]\left[\mathrm{EtSO}_{4}\right]-\mathrm{CO}_{2}$ at $303.15 \mathrm{~K}(\diamond)$ in $(\mathrm{b})$ and $323.15 \mathrm{~K}$ $(\Delta)$, and $[\mathrm{emIm}]\left[\mathrm{BF}_{4}\right]-\mathrm{CO}_{2}$ at $298.2 \mathrm{~K}(\square)$ and $313.2 \mathrm{~K}(+)$. Lines are predicted results using the UNIFAC-IL model extended in this work.

pressure at room temperature from the published experimental works, and another air component gas, $\mathrm{CO}_{2}$, is soluble in some ILs under high pressures at room temperature. Since the operation of the isoprene recovery process is under atmospheric pressure in this case, it would be reasonable to set the infinite dilution solubility coefficient of isoprene as the objective function and set the infinite dilution selectivity coefficients as thermodynamic property constraints in the IL design stage. Based on the design objective functions and the constraints on the IL structure and properties, the CAILD can be formulated as a mixed-integer nonlinear programming (MINLP) problem (which is summarized in Table 2).

To predict the $T_{\mathrm{m}}$ and $\eta$ of ILs, group contribution-based models developed by Lazzús ${ }^{69}$ and our group ${ }^{70}$ are employed, respectively. By solving the formulated MINLP problem, we find that all top optimal ILs from 248742 structural constrained ILs are the combinations of cation subgroup $\left[\mathrm{C}_{3} \mathrm{H}_{7} \mathrm{~N}\right]$ and anion group $[\mathrm{DMP}]$, which can be explained based on the desired interactions between them and the groups of isoprene and the other gas components (i.e., $\mathrm{N}_{2}, \mathrm{O}_{2}, \mathrm{CO}_{2}$ ) for the separation purpose. Although more identified optimal ILs (e.g., 7 ILs, 10 ILs) can be evaluated by the process simulation method, only top-six optimal ILs are selected as solvent candidates for their further performance evaluation as this is enough to demonstrate the performance of the identified ILs, as well as the reliability of the CAILD solution. The detailed information about the identified optimum ILs from the CAILD solution are presented in Table 3. Their melting points and viscosities are less than 295 (K) and 50 (cP), respectively, as expected from the imposed constraints. The designed targets (i.e., infinite dilution solubility coefficients) of the ILs are ranked as follows: $\left[\mathrm{N}_{1,1,3,0}\right][\mathrm{DMP}]>\left[\mathrm{N}_{1,3,0,0-\mathrm{C}=\mathrm{C}}\right]$. $[\mathrm{DMP}]>\left[\mathrm{N}_{1,2,3,0}\right][\mathrm{DMP}]>\left[\mathrm{N}_{2,3,0,0-\mathrm{C}=\mathrm{C}}\right][\mathrm{DMP}]=$ $\left[\mathrm{N}_{1,3,0,1-\mathrm{C}=\mathrm{C}}\right][\mathrm{DMP}]>\left[\mathrm{N}_{1,3,3,0}\right][\mathrm{DMP}]$. Moreover, ammonium-based cations generally have lower toxicity compared to that of the aromatic cations such as imidazolium and pyridinium rings, ${ }^{26}$ which could improve the availability of these designed ILs in terms of environmental and health concerns.

\section{PROCESS DESIGN AND SIMULATION}

Two metabolic pathways, i.e., the 2C-methyl-D-erythritol 4phosphate (MEP) pathway and the mevalonic acid (MVA) pathway, are known to synthesize isoprene. ${ }^{71-73}$ So far, the MVA pathway is the best-characterized one as it has been

\section{Table 2. CAILD-Based MINLP Problem Formulation}

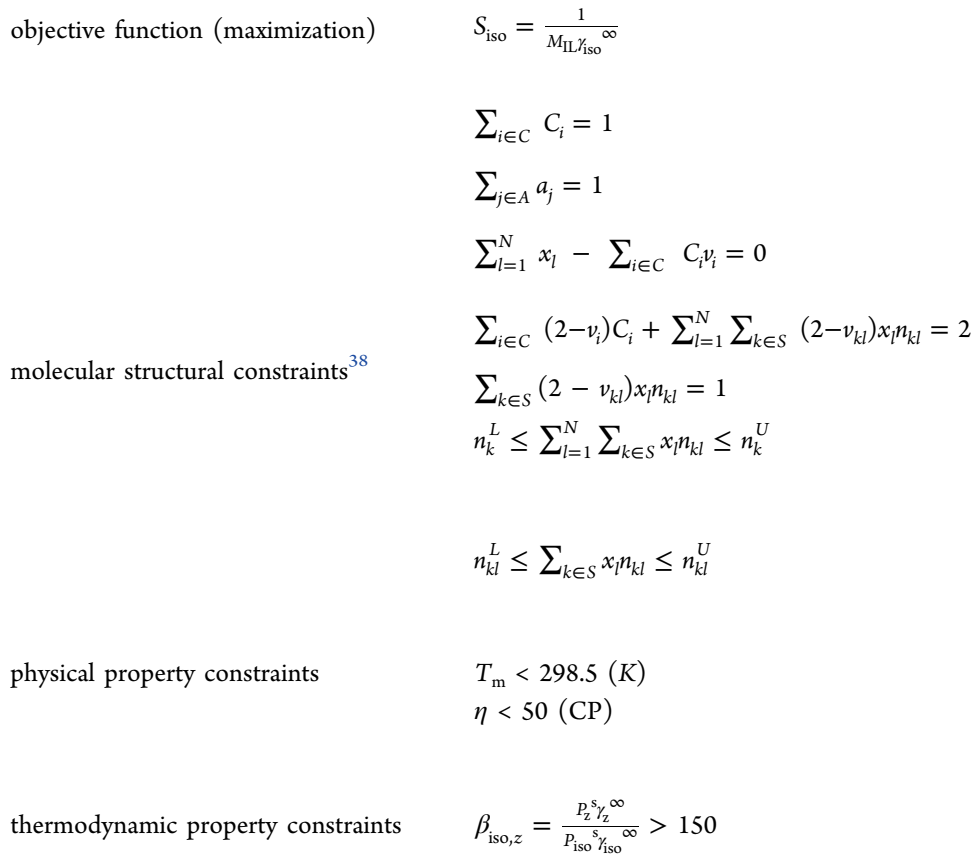

$S_{\text {iso, }}$ infinite dilution solubility coefficient of isoprene

$M_{\text {IL }}$, molar mass of IL

$\gamma_{\text {iso }}{ }^{\infty}$, infinite dilution activity coefficient of isoprene

$i$, cation; $j$, anion; $k$, substituent

$c_{i}$, occurrence of cation $i$

$a_{j}$, occurrence of anion $j$

$C$, set of cations; $A$, set of anions

$S$, set of substituents; $l$, side chains

$x_{l}$, occurrence of side chain $l$

$v_{i}$, valence of cation $i$

$v_{k l}$, valence of substituent $k$ in side chain $l$

$n_{k l}$, number of substituent $k$ in side chain $l$

$n_{k}^{L}$, minimum number of substituent $k$ in the whole molecule $n_{k}^{U}$, maximum number of substituent $k$ in the whole molecule $n_{k l}^{L}$, minimum number of substituent $k$ in side chain $l$

$n_{k l}^{U}$, maximum number of substituent $k$ in side chain $l$

$N$, number of side chains

$T_{\mathrm{m}}$, melting point temperature

$\eta$, viscosity

$\beta_{\text {iso }, y}$ infinite dilution selectivity coefficient

$z$, air component (i.e., $\mathrm{N}_{2}, \mathrm{O}_{2}, \mathrm{CO}_{2}$ )

$\gamma_{\mathrm{z}}{ }^{\infty}$, infinite dilution activity coefficient of air component $z$

$P_{\mathrm{z}}^{\mathrm{s}}$, vapor pressure of air component $z$

$P_{\text {iso }}$ 's, vapor pressure of isoprene 
Table 3. Detailed Information about Identified Optimum ILs from the CAILD Method

\begin{tabular}{|c|c|c|c|c|c|c|c|}
\hline ILs & Structure & $\begin{array}{l}M W \\
\left(\mathrm{~g} \cdot \mathrm{mol}^{-1}\right)\end{array}$ & $S_{\text {iso }} * 10^{2}$ & $T_{m}(K)$ & $\eta(c P)$ & & $\beta_{i s o, z}$ \\
\hline$\left[\mathrm{N}_{1,1,3,0}\right][\mathrm{DMP}]$ & $\begin{array}{cc}\mathrm{H} & \mathrm{O} \\
\mathrm{C}_{3} \mathrm{H}_{7}-\mathrm{N}^{+}-\mathrm{CH}_{3} & \mathrm{H} \\
\mathrm{H}_{3} \mathrm{C}-\mathrm{O}-\mathrm{P}-\mathrm{O}-\mathrm{CH}_{3} \\
\mathrm{CH}_{3} & 0\end{array}$ & 213.22 & 7.700 & 233.0 & 42.67 & $\begin{array}{l}\mathrm{N}_{2} \\
\mathrm{O}_{2} \\
\mathrm{CO}_{2}\end{array}$ & $\begin{array}{l}258.8 \\
373.9 \\
200.2\end{array}$ \\
\hline$\left[\mathrm{N}_{1,3,0,0-\mathrm{C}=\mathrm{C}}\right][\mathrm{DMP}]$ & 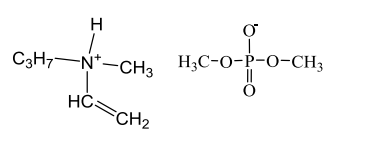 & 225.23 & 6.993 & 227.4 & 42.76 & $\begin{array}{l}\mathrm{N}_{2} \\
\mathrm{O}_{2} \\
\mathrm{CO}_{2}\end{array}$ & $\begin{array}{l}252.7 \\
329.0 \\
204.4\end{array}$ \\
\hline$\left[\mathrm{N}_{1,2,3,0}\right][\mathrm{DMP}]$ & 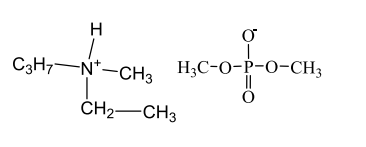 & 227.25 & 6.559 & 229.2 & 41.88 & $\begin{array}{l}\mathrm{N}_{2} \\
\mathrm{O}_{2} \\
\mathrm{CO}_{2}\end{array}$ & $\begin{array}{l}259.7 \\
341.9 \\
175.0\end{array}$ \\
\hline$\left[\mathrm{N}_{2,3,3,0-\mathrm{C}=\mathrm{C}}\right][\mathrm{DMP}]$ & 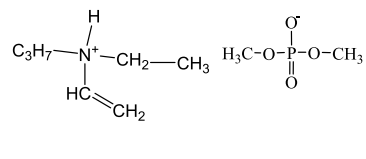 & 239.26 & 6.000 & 223.7 & 41.86 & $\begin{array}{l}\mathrm{N}_{2} \\
\mathrm{O}_{2} \\
\mathrm{CO}_{2}\end{array}$ & $\begin{array}{l}230.7 \\
302.1 \\
179.3\end{array}$ \\
\hline$\left[\mathrm{N}_{1,3,0,1-\mathrm{C}=\mathrm{C}}\right][\mathrm{DMP}]$ & 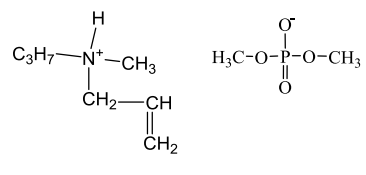 & 239.26 & 6.000 & 223.7 & 41.86 & $\begin{array}{l}\mathrm{N}_{2} \\
\mathrm{O}_{2} \\
\mathrm{CO}_{2}\end{array}$ & $\begin{array}{l}230.7 \\
302.1 \\
179.3\end{array}$ \\
\hline$\left[\mathrm{N}_{1,3,3,0}\right][\mathrm{DMP}]$ & 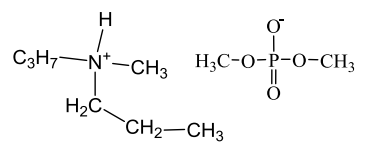 & 241.27 & 5.672 & 225.5 & 43.32 & $\begin{array}{l}\mathrm{N}_{2} \\
\mathrm{O}_{2} \\
\mathrm{CO}_{2}\end{array}$ & $\begin{array}{r}238.5 \\
315.6 \\
154.8\end{array}$ \\
\hline
\end{tabular}

exploited industrially for the production of isoprenoids in both yeast and bacteria. ${ }^{74}$ The production of bioisoprene from glucose in the presence of oxygen via $E$. coli engineered with the MVA pathway can be expressed as shown in Figure 4, where the mass yield of isoprene on glucose is $25.2 \%$.

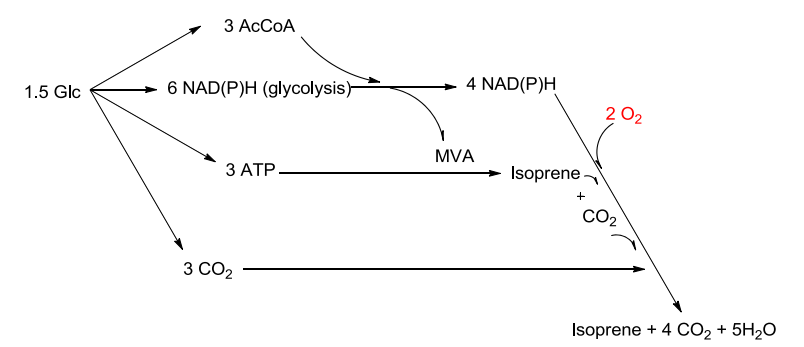

Figure 4. MVA pathway for producing isoprene from glucose in the presence of oxygen (Glc, glucose; AcCoA, acetyl-coenzyme A; $\mathrm{NADPH}$, nicotinamide adenine dinucleotide phosphate/reduced form; and ATP, adenosine triphosphate).

As presented in Figure 4, E. coli engineered with the MVA pathway to isoprene requires two $\mathrm{O}_{2}$ per isoprene produced, while four $\mathrm{CO}_{2}$ and $5 \mathrm{H}_{2} \mathrm{O}$ are generated as well. For this reason, most produced $\mathrm{H}_{2} \mathrm{O}$ should be discharged from the fermentor, while isoprene, $\mathrm{CO}_{2}$ and a small amount of $\mathrm{H}_{2} \mathrm{O}$ are removed as the fermentation off-gas (Figure 4). Depending on the components in the off-gas of the bioisoprene system, a bioisoprene production process involving the IL-based extraction recovery technique is proposed, as shown in Figure 5. In addition to recovery techniques for organic solvent-based extraction and activated carbon, a dehumidifier unit is required before the contact of the steam with IL solvents since moisture may affect their absorption capacity. After removing the water from the fermentation off-gas, the remaining vapor components are sent to the absorption column, where the normal air components (i.e., $\mathrm{N}_{2}, \mathrm{O}_{2}$, and $\mathrm{CO}_{2}$ ) escape from the top of the column and isoprene is retained by the IL solvent. Due to the big volatility difference of isoprene and the IL solvent, isoprene can be easily recovered from the IL solvent using a simple flash unit. However, the operating temperature of the flash unit is limited since isoprene decomposes at $120{ }^{\circ} \mathrm{C}$ (https:// pubchem.ncbi.nlm.nih.gov/compound/Isoprene). For this reason, here, a vacuum flash evaporation is considered to recover the product from the solvent as much as possible. Finally, a liquid isoprene product can be obtained after the condensation of vapor isoprene from the top of the flash unit.

Process simulation as a discipline uses mathematical models as a basis for analysis, prediction, testing, and detection of a process behavior unrelated to whether the process is existing in reality or not. Process simulation is there to increase the level of knowledge for a particular process and chemical engineering in general (https://simulatelive.com/simulate/steady-state/ process-simulation-as-the-key-discipline-of-chemicalengineering). In this work, Aspen Plus is employed as a simulator for the detailed process simulation, where all six optimum IL candidates identified from the CAILD method are considered. So far, ILs should be defined as pseudocomponents since they are not included to the component database in Aspen Plus. For this reason, the properties of ILs including molecular weights and critical properties need to be specified prior to performing the calculations. Meanwhile, an 


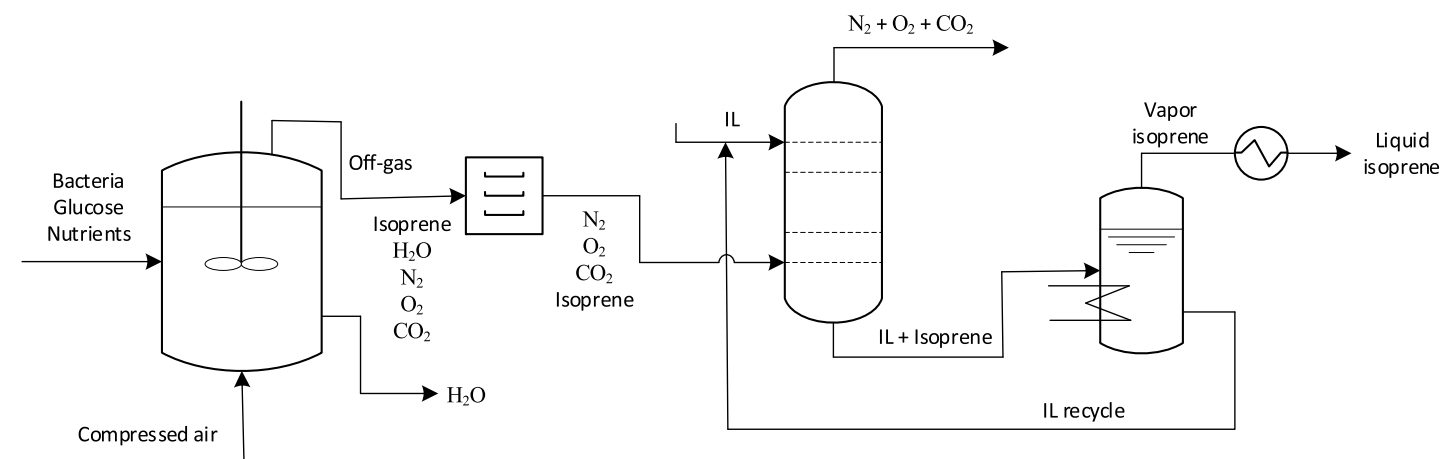

Figure 5. Bioisoprene production process using the IL-based recovery technique.

appropriate thermodynamic method is also required to simulate the process of IL-containing systems. Critical properties of ILs are calculated from the fragment contribution-corresponding states method proposed by Huang et al., ${ }^{75}$ and some temperature-dependent properties can be estimated from the method developed in our previous work. ${ }^{15}$ Meanwhile, UNIFAC is selected as the thermodynamic method for process simulation as was the case also in the design stage of CAILD. Group van der Waals parameters $\left(R_{k}, Q_{k}\right)$ and group interaction parameters $\left(\alpha_{m n}, \alpha_{n m}\right)$ required for the use of UNIFAC-IL model are taken from both the published works ${ }^{37,76}$ and the current work.

In this work, the task of the bioisoprene recovery process is to separate isoprene from $\mathrm{N}_{2}, \mathrm{O}_{2}$, and $\mathrm{CO}_{2}$ in the dehumidified off-gas by the IL solvent and then recover isoprene from the IL solvent. In this process, isoprene should be recovered as much as possible, while the other air components (i.e., $\mathrm{N}_{2}, \mathrm{O}_{2}$, and $\mathrm{CO}_{2}$ ) should be less retained. So far, isopropyl myristate is studied as the most promising organic solvent for the recovery of isoprene. Therefore, it is very important to compare the performance of the identified optimal ILs with the performance of this benchmark organic solvent. For the purposes of comparison, the bioisoprene recovery process of using isopropyl myristate as a solvent is also simulated and optimized. The simulation of this recovery process is performed in Aspen Plus (V8.6), where the absorption column is modeled by the RadFrac block and the IL regeneration unit is modeled by flash evaporation.

\section{RESULTS AND DISCUSSION}

In the design step of process simulation, key operating variables such as the number of stages and the flow rates of the solvent are optimized by sensitivity and tradeoff analyses. As demonstrated, sensitivity analyses of the flow rates of the solvent with the different number of stages $(N)$ for using $\left[\mathrm{N}_{1,3,3,0}\right][\mathrm{DMP}]$ and isopropyl myristate as solvents are provided in Figures 6 and 7, respectively. As expected, the retained isoprene (\%) increases with increasing solvent flow rate and the number of column stages. As shown in Figure 6, the IL-based process has a large difference in retained isoprene (\%) with different numbers of stages in the region of a low solvent flow rate. In contrast, this happens in the region of high solvent flow rate using isopropyl myristate (see Figure 7). Nonetheless, $N=4$ is the optimal number of stages for both processes since the difference of retained isoprene (\%) is very small at high product recovery region between $N=4$ and 5 . The simulation results with IL $\left(\left[\mathrm{N}_{1,3,3,0}\right][\mathrm{DMP}]\right)$ show much better process performance than that with isopropyl myristate

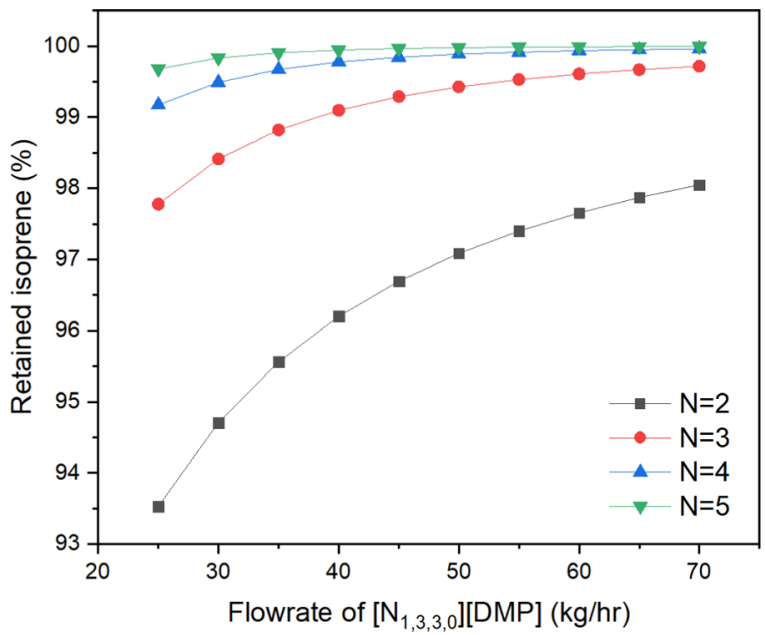

Figure 6. Retained isoprene (\%) against the mass flow rate of $\left[\mathrm{N}_{1,3,3,0}\right][\mathrm{DMP}]$ in the absorption column with different numbers of column stages $(N)$.

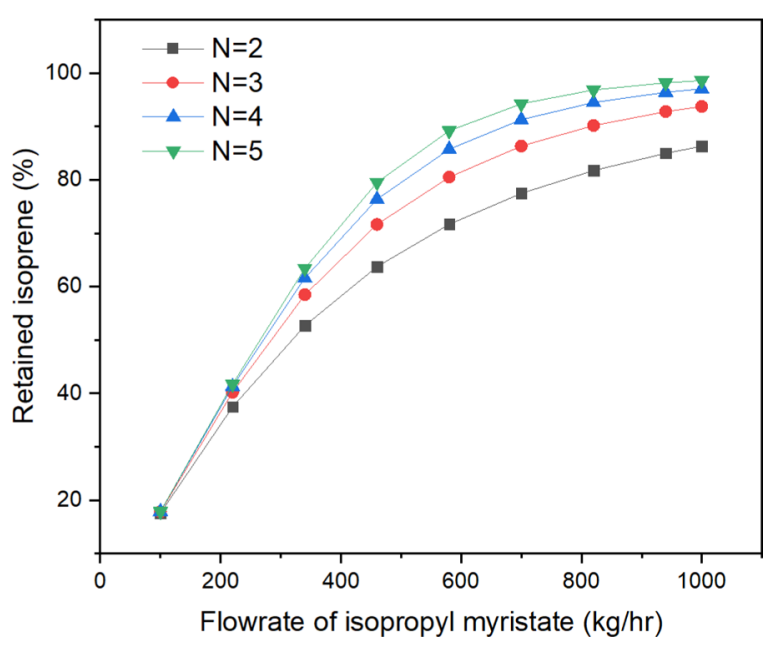

Figure 7. Retained isoprene (\%) against the mass flow rate of isopropyl myristate in the absorption column with different numbers of column stages $(N)$.

in terms of the solvent flow rate and the percentage of product recovery.

To evaluate the influence of the solvent flow rate on the other containing gas components in off-gas, the analysis of the recovery percentage of isoprene and retained air gas components $\left(\mathrm{N}_{2}+\mathrm{O}_{2}+\mathrm{CO}_{2}\right)$ with a certain number of stages $(N=4)$ is also provided. As shown in Figures 8 and 9, 


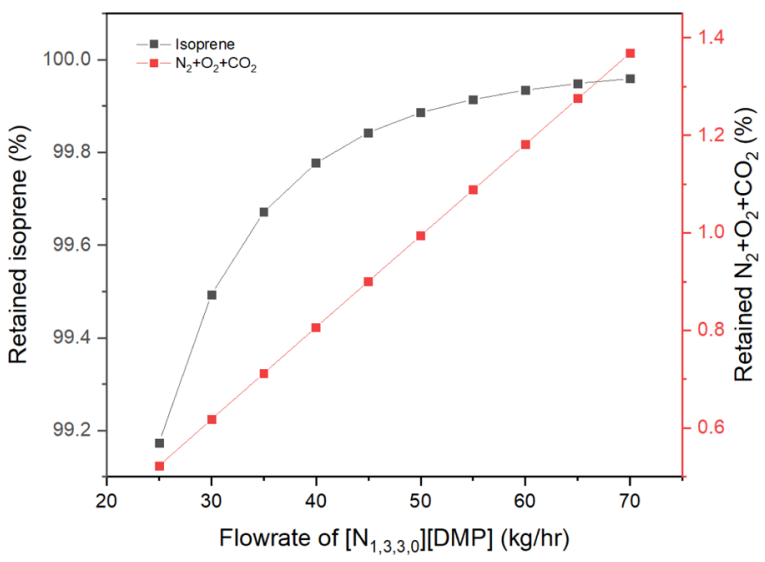

Figure 8. Retained isoprene and $\mathrm{N}_{2}+\mathrm{O}_{2}+\mathrm{CO}_{2}$ (\%) against the mass flow rate of $\left[\mathrm{N}_{1,3,3,0}\right][\mathrm{DMP}]$ in the absorption column with the number of column stages $N=4$.

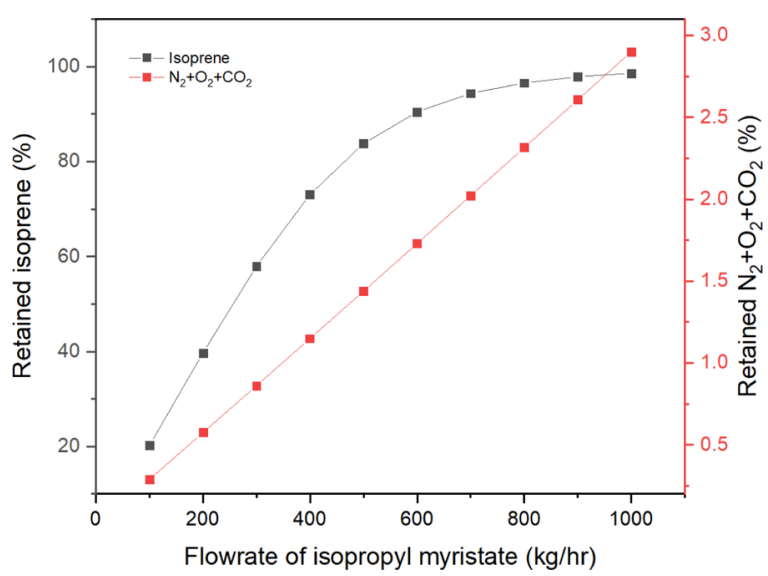

Figure 9. Retained isoprene and $\mathrm{N}_{2}+\mathrm{O}_{2}+\mathrm{CO}_{2}$ (\%) against the mass flow rate of isopropyl myristate in the absorption column with the number of column stages $N=4$.

air gas components exhibit a linear relationship with the flow rates of both $\left[\mathrm{N}_{1,3,3,0}\right][\mathrm{DMP}]$ and isopropyl myristate. The simulation results indicate that these gas components are generally more easily to be retained in isopropyl myristate than in $\left[\mathrm{N}_{1,3,3,0}\right][\mathrm{DMP}]$ with the same isoprene recovery, showing the better selectivity of $\left[\mathrm{N}_{1,3,3,0}\right][\mathrm{DMP}]$ for isoprene over the other air gas components. Based on the tradeoff analysis, the number of stages and the flow rate of the solvent yielding the best performance of isoprene recovery and retained air components can be achieved for certain cases.

Considering that the percent isoprene $\left(\varnothing_{\text {iso }}\right)$ and the levels of other gases such as $\mathrm{CO}_{2}$ and $\mathrm{O}_{2}$ in the off-gas have significant impact on its separation process, a sensitivity analysis on the composition of the off-gas is also necessary. According to the MVA pathway to produce isoprene, the composition of the dehumidified off-gas can be calculated from the flow rate of compressed air and the volumetric productivity of isoprene. Using deep-tank culture conditions, a volumetric productivity of $2 \mathrm{~g} /(\mathrm{L} \mathrm{h})$ with a yield of $11 \%$ isoprene from glucose has been obtained in Cervin's work. ${ }^{77}$ Based on this condition, five bioisoprene systems with different percentages of isoprene are studied in this work, as given in Table 4. Sensitivity analyses of different volume percentages of isoprene using IL $\left(\left[\mathrm{N}_{1,3,3,0}\right][\mathrm{DMP}]\right)$ and isopropyl myristate are presented in Figures 10 and 11, respectively. The simulation
Table 4. Compositions of Studied Off-Gas Systems for Sensitivity Analysis

\begin{tabular}{ccccc} 
off-gas & $\begin{array}{c}\text { isoprene } \\
(\% \mathrm{v} / \mathrm{v})\end{array}$ & $\begin{array}{c}\mathrm{N}_{2} \\
(\% \mathrm{v} / \mathrm{v})\end{array}$ & $\begin{array}{c}\mathrm{O}_{2} \\
(\% \mathrm{v} / \mathrm{v})\end{array}$ & $\begin{array}{c}\mathrm{CO}_{2} \\
(\% \mathrm{v} / \mathrm{v})\end{array}$ \\
$\begin{array}{c}\text { composition of } \\
\text { system 1 }\end{array}$ & 1.89 & 75.47 & 15.09 & 7.55 \\
$\begin{array}{c}\text { composition of } \\
\text { system 2 } \\
\text { composition of } \\
\text { system 3 }\end{array}$ & 2.75 & 73.40 & 12.84 & 11.01 \\
$\begin{array}{c}\text { composition of } \\
\text { system 4 }\end{array}$ & 3.57 & 71.43 & 10.71 & 14.29 \\
$\begin{array}{c}\text { composition of } \\
\text { system 5 }\end{array}$ & 5.35 & 69.56 & 8.70 & 17.39 \\
\hline
\end{tabular}

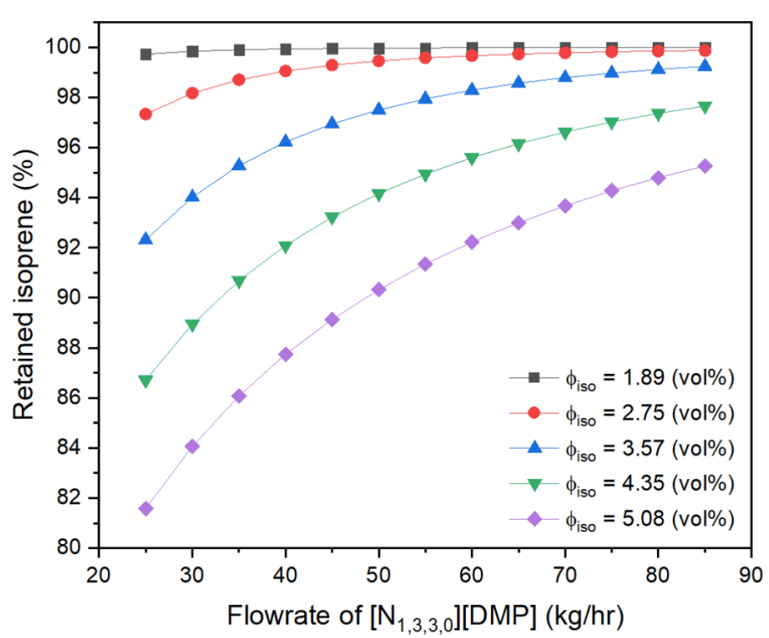

Figure 10. Retained isoprene (\%) against the mass flow rate of $\left[\mathrm{N}_{1,3,3,0}\right][\mathrm{DMP}]$ in the absorption column with different percentages of isoprene in the off-gas $(N=4)$.

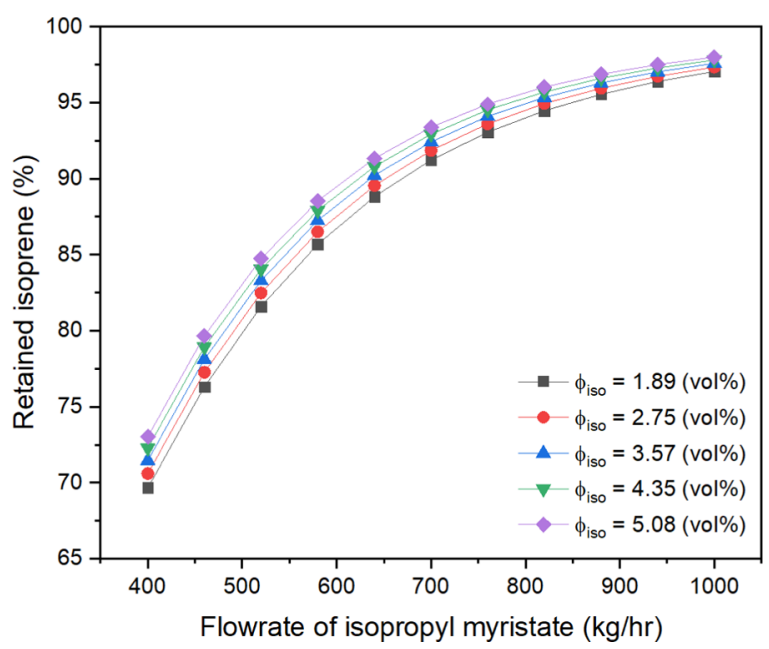

Figure 11. Retained isoprene and $\mathrm{CO}_{2}(\%)$ against the mass flow rate of isopropyl myristate in the absorption column with different percentages of isoprene in the off-gas $(N=4)$.

results show that the solvent flow rate in the IL-based process is more sensitive to the composition of the bioisoprene system than that in the isopropyl myristate -based process. This can be explained by the much lower flow rate of IL, which is required to achieve the same recovery of isoprene. The simulation information about the recovery process for the bioisoprene system using all identified ILs and isopropyl myristate is 
summarized in Table 5. The simulation results show that all six ILs have much better process performance than that of

Table 5. Simulation Results for the Bioisoprene Recovery Process Using Different Solvents ${ }^{a, b, c}$

\begin{tabular}{lccc}
\multicolumn{1}{c}{ solvents } & $\begin{array}{c}\text { flow rate of the } \\
\text { solvent }(\mathrm{kg} / \mathrm{h})\end{array}$ & $\begin{array}{c}\text { recovery } \\
\text { ratio }(\%)\end{array}$ & $\begin{array}{c}\text { purity of the } \\
\text { product }(\%)\end{array}$ \\
{$\left[\mathrm{N}_{1,1,3,0}\right][\mathrm{DMP}]$} & 48 & 85.05 & 99.50 \\
{$\left[\mathrm{~N}_{1,3,0,0-\mathrm{C}=\mathrm{C}]}\right.$} & 56 & 84.73 & 99.50 \\
{$[\mathrm{DMP}]$} & & & \\
{$\left[\mathrm{N}_{1,2,3,0}\right][\mathrm{DMP}]$} & 53 & 84.28 & 99.50 \\
{$\left[\mathrm{~N}_{2,3,0,0-\mathrm{C}=\mathrm{C}]}\right]$} & 57 & 83.17 & 99.50 \\
{$[\mathrm{DMP}]$} & & & \\
{$\left[\mathrm{N}_{1,3,0,1-\mathrm{C}=\mathrm{C}}\right]$} & 57 & 83.17 & 99.50 \\
{$[\mathrm{DMP}]$} & & & 99.50 \\
{$\left[\mathrm{~N}_{1,3,3,0}\right][\mathrm{DMP}]$} & 63 & 82.84 & 87.15 \\
$\begin{array}{c}\text { isopropyl } \\
\text { myristate }\end{array}$ & 340 & 76.77 &
\end{tabular}

${ }^{a}$ Flow rate of the dehumidified off-gas, $100(\mathrm{~kg} / \mathrm{h}) .{ }^{b}$ Composition of the dehumidified off-gas ( $\% \mathrm{v} / \mathrm{v})$ : isoprene, 4.35; $\mathrm{N}_{2}, 69.56 ; \mathrm{O}_{2}, 8.70$; $\mathrm{CO}_{2}$, 17.39. ${ }^{C}$ Unit operating conditions: absorption column $(P=1$ bar, $N=4)$; flash unit $\left(P=0.01 \mathrm{bar}, T=100^{\circ} \mathrm{C}\right)$.

isopropyl myrisate and that $\left[\mathrm{N}_{1,1,3,0}\right][\mathrm{DMP}]$ is identified as the best IL with the lowest solvent flow rate and the highest recovery ratio of isoprene. We should note that the lower and upper explosion limits of isoprene in air are $1(\% \mathrm{v} / \mathrm{v})$ and 9.7 $(\% \mathrm{v} / \mathrm{v})$, respectively. However, based on the literature search performed, studies on the explosion limits in the bioisoprene system have not yet been reported and this must be investigated before any practical implementation.

\section{CONCLUSIONS}

In summary, we have investigated the possibility of using ILs as solvents for the recovery of isoprene from fermentation off-gas. To describe the thermodynamic behavior of bioisoprene systems involving ILs, the UNIFAC-IL model that combines gas-organic chemicals is extended using a wide range of experimental data from published works and a certain number of pseudo-experimental data from COSMO calculations. Based on this extended thermodynamic model, a CAILD-MINLP problem is formulated and solved, from where six out of 248742 structural constrained ILs are selected and further evaluated by means of process simulations in Aspen Plus. For comparison purposes, the isoprene recovery process using the typically used isopropyl myristate is also simulated and optimized. Simulation results show that all six ILs have much better process performance than that of isopropyl myristate and that $\left[\mathrm{N}_{1,1,3,0}\right][\mathrm{DMP}]$ is identified as the best IL with the lowest solvent flow rate and the highest recovery ratio of isoprene.

Although experimental verification of these ILs is required for their further industrial application, the process simulation results indicate that the IL-based recovery technique has the potential to improve the economic and technical competitiveness of the bioisoprene production process. In this work, we find that all identified ILs are the combinations of a cation subgroup $\left[\mathrm{C}_{3} \mathrm{H}_{7} \mathrm{~N}\right]$ and an anion group $[\mathrm{DMP}]$ because of their interactions with the groups of isoprene and other gas components in the off-gas, which could be a guidance for the experiment works in the future. We hope that the promising performance of the identified ILs will invite more systematic experimental validations. This work is focused on the bioisoprene recovery process; however, the UNIFAC-IL model and the design method can potentially be extended to the other bioseparation processes such as bio-oxidation of alcohols and bio-oxidation of 5-hydroxymethyl-2-furfural, where the bioproducts need to be recovered from diluted solutions.

\section{APPENDIX A. ORIGINAL UNIFAC MODEL}

UNIFAC is a functional-group-based semiempirical prediction method, where the activity coefficient for each species in the system is split into two components: a combinatorial $\gamma_{i}^{\mathrm{C}}$ and a residual component $\gamma_{i}^{\mathrm{R}}$. For the molecule $i$, the activity coefficients are broken down as follows

$$
\ln \gamma_{i}=\ln \gamma_{i}^{\mathrm{C}}+\ln \gamma_{i}^{\mathrm{R}}
$$

The combinatorial component of the activity is related to the entropic effects accounting for the size and shape of molecules, which can be expressed via the van der Waals volume $\left(R_{k}\right)$ and surface area $\left(Q_{k}\right)$ parameters of each functional group. The residual component of the activity is due to energetic interactions between groups present in the system and represents the enthalpic contribution and is expressed as the binary interaction parameters $\left(\alpha_{n m}, \alpha_{\mathrm{mn}}\right) \cdot \gamma_{i}^{\mathrm{C}}$ and $\gamma_{i}^{\mathrm{R}}$ can be calculated by eqs $\mathrm{A} 2-\mathrm{A} 6$ and $\mathrm{A} 7-\mathrm{A} 12$, respectively.

$$
\begin{aligned}
& \ln \gamma_{i}^{C}=1-V_{i}+\ln V_{i}-5 q_{i}\left(1-\frac{V_{i}}{F_{i}}+\ln \left(\frac{V_{i}}{F_{i}}\right)\right) \\
& F_{i}=\frac{q_{i}}{\sum_{j} q_{j} x_{j}} \\
& V_{i}=\frac{r_{i}}{\sum_{j} r_{j} x_{j}} \\
& q_{i}=\sum_{k} v_{k}^{(i)} Q_{k} \\
& r_{i}=\sum_{k} v_{k}^{(i)} R_{k}
\end{aligned}
$$

where $F_{\mathrm{i}}$ and $V_{\mathrm{i}}$ represent auxiliary properties for component $i$; the pure component parameters $q_{i}$ and $r_{i}$, respectively, denote the relative molecular surface areas and molecular van der Waals volumes, which are obtained from the sum of the group area $Q_{k}$ and group volume $R_{k}$ parameters, respectively. $v_{k}{ }^{(i)}$ is the number of groups of type $k$ in molecule $i$.

$$
\begin{aligned}
& \ln \gamma_{i}^{\mathrm{R}}=\sum_{k} v_{k}^{(i)}\left(\ln \Gamma_{k}-\ln \Gamma_{k}^{(i)}\right) \\
& \ln \Gamma_{k}=Q_{k}\left(1-\ln \left(\sum_{m} \theta_{m} \psi_{m k}\right)-\sum_{m} \frac{\theta_{m} \psi_{k m}}{\sum_{n} \theta_{n} \psi_{n m}}\right. \\
& \theta_{m}=\frac{Q_{m} X_{m}}{\sum_{n} Q_{n} X_{n}} \\
& X_{m}=\frac{\sum_{i} v_{m}^{(i)} x_{i}}{\sum_{i} \sum_{k} v_{k}^{(i)} x_{i}} \\
& \psi_{n m}=\exp \left[-\left(\alpha_{n m} / T\right)\right]
\end{aligned}
$$




$$
\psi_{m n}=\exp \left[-\left(\alpha_{m n} / T\right)\right]
$$

where $\Gamma_{k}$ and $\Gamma_{k}^{(i)}$ denote the residual activity coefficient of group $k$ and the residual activity coefficient of group $k$ in pure component $i$, respectively; $\theta_{m}$ is the fraction of group $m$ in a mixture of the liquid phase and $X_{m} / X_{n}$ is the fraction of group $m$ or $n$ in the mixture; $\psi_{n m}$ and $\psi_{m n}$ are the group interaction parameters that can be calculated by eqs A11 and AAA12 based on the value of UNIFAC group interaction parameters $\left(\alpha_{n m}, \alpha_{m n}\right)$ between groups $m$ and $n$.

\section{APPENDIX B. PHASE EQUILIBRIUM EQUATIONS}

The vapor-liquid equilibrium (VLE) conditions in phase equilibrium can be expressed as

$$
P y_{i} \varphi_{i}=P_{i}^{\mathrm{s}} x_{i} \gamma_{i}
$$

where $P$ is the system pressure and $\gamma_{i}$ is the activity coefficient of component $i ; y_{i}$, and $x_{i}$ denote the mole fractions of component $i$ in vapor and liquid phases, respectively; the fugacity coefficient of component $i\left(\varphi_{i}\right)$ that was calculated by the Redlich-Kwong equation of state and the saturated vapor pressure of component $i\left(P_{i}^{s}\right)$ can be estimated by the DIPPR equation (see eq A14)

$$
P_{i}^{\mathrm{s}}(\mathrm{Pa})=\exp \left[A_{i}+\left(B_{i} / T\right)+C_{i} \ln T+D_{i} T^{E_{i}}\right]
$$

where the values of the different compound-specific parameters $\left(A_{i}, B_{i}, C_{i}, D_{i}\right.$, and $\left.E_{i}\right)$ are taken from the DIPPR database (https://dippr.aiche.org/SampleDb).

\section{ASSOCIATED CONTENT}

\section{SI Supporting Information}

The Supporting Information is available free of charge at https://pubs.acs.org/doi/10.1021/acs.iecr.0c00146.

Abbreviations and names of the involved IL cations and anions (Table S1); information about all experimental and pseudo-experimental data for the extension of the UNIFAC-IL model (Table S2); interaction parameters of the extended UNIFAC-IL model (Table S3); and detailed information about the process simulation in Aspen Plus (Table S4) (XLSX)

\section{AUTHOR INFORMATION}

\section{Corresponding Author}

John M. Woodley - Department of Chemical and Biochemical Engineering, Technical University of Denmark, DK-2800 Lyngby, Denmark; 이이이.org/0000-0002-7976-2483; Phone: +45 45252885; Email: jw@kt.dtu.dk

\section{Authors}

Yuqiu Chen - Department of Chemical and Biochemical Engineering, Technical University of Denmark, DK-2800 Lyngby, Denmark; 이 orcid.org/0000-0003-0706-160X

Xinyan Liu - Department of Chemical and Biochemical Engineering, Technical University of Denmark, DK-2800 Lyngby, Denmark; Beijing Key Laboratory of Ionic Liquids Clean Process, CAS Key Laboratory of Green Process and Engineering, State Key Laboratory of Multiphase Complex Systems, Institute of Process Engineering, Chinese Academy of Sciences, Beijing 100190, China

Georgios M. Kontogeorgis - Department of Chemical and Biochemical Engineering, Technical University of Denmark, DK2800 Lyngby, Denmark; 이 orcid.org/0000-0002-7128-1511
Complete contact information is available at:

https://pubs.acs.org/10.1021/acs.iecr.0c00146

\section{Notes}

The authors declare no competing financial interest.

\section{ACKNOWLEDGMENTS}

This research work was supported by the China Scholarship Council (No. 201708440264) and the Technical University of Denmark.

\section{REFERENCES}

(1) Whited, G. M.; Feher, F. J.; Benko, D. A.; Cervin, M. A.; Chotani, G. K.; McAuliffe, J. C.; LaDuca, R. J.; Ben-Shoshan, E. A.; Sanford, K. J. Technology update: development of a gas-phase bioprocess for isoprene-monomer production using metabolic pathway engineering. Ind. Biotechnol. 2010, 6, 152-163.

(2) Huibin, Z.; Liu, H.; Aboulnaga, E.; Liu, H.; Cheng, T.; Xian, M. Microbial Production of Isoprene: Opportunities and Challenges. Ind. Biotechnol. Prod. Processes 2017, 473-504.

(3) Ushio, S. Extract isoprene with DMF. Chem. Eng. 1972, 79, 8283.

(4) Abdelrahman, O. A.; Park, D. S.; Vinter, K. P.; Spanjers, C. S.; Ren, L.; Cho, H. J.; Zhang, K.; Fan, W.; Tsapatsis, M.; Dauenhauer, P. $\mathrm{J}$. Renewable isoprene by sequential hydrogenation of itaconic acid and dehydra-decyclization of 3-methyl-tetrahydrofuran. ACS Catal. 2017, 7, 1428-1431.

(5) Lundberg, D. J.; Lundberg, D. J.; Zhang, K.; Dauenhauer, P. J. Process Design and Economic Analysis of Renewable Isoprene from Biomass via Mesaconic Acid. ACS Sustainable Chem. Eng. 2019, 7, 5576-5586.

(6) Morais, A. R. C.; Dworakowska, S.; Reis, A.; Gouveia, L.; Matos, C. T.; Bogdal, D.; Bogel-Łukasik, R. Chemical and biological-based isoprene production: Green metrics. Catal. Today 2015, 239, 38-43.

(7) King, C. J. Separations in the production of high-volume fuels and chemicals by biological processing. In Proceedings of the 25th Intersociety Energy Conversion Engineering Conference; IEEE, 1990; Vol. 3, pp 509-513.

(8) Ruhl, M. J. Recover VOCs via adsorption on activated carbon. Chem. Eng. Prog. 1993, 89.

(9) McAuliffe, J. C.; Paramonov, S. E.; Sanford, K. J. Fuel Compositions Comprising Isoprene Derivatives. U.S. Patent US8,450,5492013.

(10) Rogers, R. D.; Seddon, K. R. Ionic liquids-solvents of the future? Science 2003, 302, 792-793.

(11) Hansmeier, A. R.; Meindersma, G. W.; de Haan, A. B. Desulfurization and denitrogenation of gasoline and diesel fuels by means of ionic liquids. Green Chem. 2011, 13, 1907-1913.

(12) George, A.; Brandt, A.; Tran, K.; Zahari, S. M. N. S.; KleinMarcuschamer, D.; Sun, N.; Sathitsuksanoh, N.; Shi, J.; Stavila, V.; Parthasarathi, R.; et al. Design of low-cost ionic liquids for lignocellulosic biomass pretreatment. Green Chem. 2015, 17, 17281734.

(13) Gomes, J. M.; Silva, S. S.; Reis, R. L. Biocompatible ionic liquids: fundamental behaviours and applications. Chem. Soc. Rev. 2019, 48, 4317-4335.

(14) Chen, L.; Sharifzadeh, M.; Mac Dowell, N.; Welton, T.; Shah, N.; Hallett, J. P. Inexpensive ionic liquids: $\left[\mathrm{HSO}_{4}\right]^{-}$-based solvent production at bulk scale. Green Chem. 2014, 16, 3098-3106.

(15) Chen, Y.; Koumaditi, E.; Gani, R.; Kontogeorgis, G. M.; Woodley, J. M. Computer-Aided Design of Ionic Liquids for Hybrid Process Schemes. Comput. Chem. Eng. 2019, 130, No. 106556.

(16) Ventura, S. P.; e Silva, F. A.; Quental, M. V.; Mondal, D.; Freire, M. G.; Coutinho, J. A. P. Ionic-liquid-mediated extraction and separation processes for bioactive compounds: past, present, and future trends. Chem. Rev. 2017, 117, 6984-7052.

(17) Plechkova, N. V.; Seddon, K. R. Applications of ionic liquids in the chemical industry. Chem. Soc. Rev. 2008, 37, 123-150. 
(18) Freire, M. G.; Claudio, A. F. M.; Araujo, J. M. M.; Coutinho, J. A. P.; Marrucho, I. M.; Lopes, J. N. C.; Rebelo, L. P. N. Aqueous biphasic systems: a boost brought about by using ionic liquids. Chem. Soc. Rev. 2012, 41, 4966-4995.

(19) Fadeev, A. G.; Meagher, M. M. Opportunities for ionic liquids in recovery of biofuels. Chem. Commun. 2001, 295-296.

(20) Brandt-Talbot, A.; Gschwend, F. J. V.; Fennell, P. S.; Lammens, T. M.; Tan, B.; Weale, J.; Hallett, J. P. An economically viable ionic liquid for the fractionation of lignocellulosic biomass. Green Chem. 2017, 19, 3078-3102.

(21) Simoni, L. D.; Chapeaux, A.; Brennecke, J. F.; Stadtherr, M. A. Extraction of biofuels and biofeedstocks from aqueous solutions using ionic liquids. Comput. Chem. Eng. 2010, 34, 1406-1412.

(22) Zhao, D.; Liao, Y.; Zhang, Z. Toxicity of ionic liquids. Clean: Soil, Air, Water 2007, 35, 42-48.

(23) Coleman, D.; Gathergood, N. Biodegradation studies of ionic liquids. Chem. Soc. Rev. 2010, 39, 600-637.

(24) Pham, T. P. T.; Cho, C.-W.; Yun, Y.-S. Environmental fate and toxicity of ionic liquids: a review. Water Res. 2010, 44, 352-372.

(25) Petkovic, M.; Seddon, K. R.; Rebelo, L. P. N.; Pereira, C. S. Ionic liquids: a pathway to environmental acceptability. Chem. Soc. Rev. 2011, 40, 1383-1403.

(26) Stolte, S.; Matzke, M.; Arning, J.; Böschen, A.; Pitner, W.-R.; Welz-Biermann, U.; Jastorff, B.; Ranke, J. Effects of different head groups and functionalised side chains on the aquatic toxicity of ionic liquids. Green Chem. 2007, 9, 1170-1179.

(27) Karunanithi, A. T.; Mehrkesh, A. Computer-aided design of tailor-made ionic liquids. AIChE J. 2013, 59, 4627-4640.

(28) Kato, R.; Gmehling, J. Systems with ionic liquids: Measurement of VLE and $\gamma \infty$ data and prediction of their thermodynamic behavior using original UNIFAC, mod. UNIFAC (Do) and COSMO-RS (Ol). J. Chem. Thermodyn. 2005, 37, 603-619.

(29) Lei, Z.; Zhang, J.; Li, Q.; Chen, B. UNIFAC model for ionic liquids. Ind. Eng. Chem. Res. 2009, 48, 2697-2704.

(30) Klamt, A. Conductor-like screening model for real solvents: a new approach to the quantitative calculation of solvation phenomena. J. Phys. Chem. A. 1995, 99, 2224-2235.

(31) Klamt, A.; Jonas, V.; Bürger, T.; Lohrenz, J. C. W. Refinement and parametrization of COSMO-RS. J. Phys. Chem. A 1998, 102, 5074-5085.

(32) Klamt, A.; Eckert, F. COSMO-RS: a novel and efficient method for the a priori prediction of thermophysical data of liquids. Fluid Phase Equilib. 2000, 172, 43-72.

(33) Lei, Z.; Dai, C.; Liu, X.; Xiao, L.; Chen, B. Extension of the UNIFAC model for ionic liquids. Ind. Eng. Chem. Res. 2012, 51, 12135-12144.

(34) Yu, G.; Dai, C.; Lei, Z. Modified UNIFAC-Lei Model for Ionic Liquid-CH4 Systems. Ind. Eng. Chem. Res. 2018, 57, 7064-7076.

(35) Dong, Y.; Huang, S.; Guo, Y.; Lei, Z. COSMO-UNIFAC model for ionic liquids. AIChE J. 2020, 66, No. e16787.

(36) Zhu, R.; Taheri, M.; Zhang, J.; Lei, Z. Extension of the COSMO-UNIFAC Thermodynamic Model. Ind. Eng. Chem. Res. 2020, 59, 1693-1701.

(37) Roughton, B. C.; Christian, B.; White, J.; Camarda, K. V.; Gani, R. Simultaneous design of ionic liquid entrainers and energy efficient azeotropic separation processes. Comput. Chem. Eng. 2012, 42, 248262.

(38) Simoni, L. D.; Lin, Y.; Brennecke, J. F.; Stadtherr, M. A. Modeling liquid- liquid equilibrium of ionic liquid systems with NRTL, electrolyte-NRTL, and UNIQUAC. Ind. Eng. Chem. Res. 2008, 47, 256-272.

(39) Santiago, R. S.; Santos, G. R.; Aznar, M. UNIQUAC correlation of liquid-liquid equilibrium in systems involving ionic liquids: The DFT-PCM approach. Fluid Phase Equilib. 2009, 278, 54-61.

(40) Lei, Z.; Dai, C.; Wang, W.; Chen, B. UNIFAC model for ionic liquid-CO2 systems. AIChE J. 2014, 60, 716-729.

(41) Hector, T.; Gmehling, J. Present status of the modified UNIFAC model for the prediction of phase equilibria and excess enthalpies for systems with ionic liquids. Fluid Phase Equilib. 2014, $371,82-92$.

(42) Song, Z.; Zhang, C.; Qi, Z.; Zhou, T.; Sundmacher, K. Computer-aided design of ionic liquids as solvents for extractive desulfurization. AIChE J. 2018, 64, 1013-1025.

(43) Liu, X.; Zhou, T.; Zhang, X.; Zhang, S.; Liang, X.; Gani, R.; Kontogeorgis, G. M. Application of COSMO-RS and UNIFAC for ionic liquids based gas separation. Chem. Eng. Sci. 2018, 192, 816828.

(44) Fredenslund, A.; Jones, R. L.; Prausnitz, J. M. Groupcontribution estimation of activity coefficients in nonideal liquid mixtures. AIChE J. 1975, 21, 1086-1099.

(45) Bondi, A. van der Waals volumes and radii. J. Phys. Chem. B. 1964, 68, 441-451.

(46) Nocon, G.; Weidlich, U.; Gmehling, J.; Onken, U. Prediction of Gas Solubilities by a Modified UNIFAC-Equation. Ber. Bunsen-Ges. Phys. Chem. 1983, 87, 17-23.

(47) Hansen, H. K.; Rasmussen, P.; Fredenslund, A.; Schiller, M.; Gmehling, J. Vapor-liquid equilibria by UNIFAC group contribution. 5. Revision and extension. Ind. Eng. Chem. Res. 1991, 30, 2352-2355.

(48) Chen, Y.; Gani, R.; Kontogeorgis, G. M.; Woodley, J. M. Integrated ionic liquid and process design involving azeotropic separation processes. Chem. Eng. Sci. 2019, 203, 402-414.

(49) Zhou, L.; Shang, X.; Fan, J.; Wang, J. Solubility and selectivity of $\mathrm{CO} 2$ in ether-functionalized imidazolium ionic liquids. J. Chem. Thermodyn. 2016, 103, 292-298.

(50) Zhang, S.; Yuan, X.; Chen, Y.; Zhang, X. Solubilities of CO2 in 1-butyl-3-methylimidazolium hexafluorophosphate and 1,1,3,3-tetramethylguanidium lactate at elevated pressures. J. Chem. Eng. Data 2005, 50, 1582-1585

(51) Muldoon, M. J.; Aki, S. N. V. K.; Anderson, J. L.; Dixon, J. K.; Brennecke, J. F. Improving carbon dioxide solubility in ionic liquids. J. Phys. Chem. B 2007, 111, 9001-9009.

(52) Zhou, L.; Fan, J.; Shang, X.; Wang, J. Solubilities of CO2, H2, $\mathrm{N} 2$ and $\mathrm{O} 2$ in ionic liquid 1-n-butyl-3-methylimidazolium heptafluorobutyrate. J. Chem. Thermodyn. 2013, 59, 28-34.

(53) Chen, Y.; Mutelet, F.; Jaubert, J.-N. Solubility of CO2 in 1butyl-3-methylimidazolium diethylene-glycolmonomethylethersulfate and trihexyl (tetradecyl) phosphonium dodecyl-benzenesulfonate. Fluid Phase Equilib. 2013, 354, 191-198.

(54) Revelli, A.-L.; Mutelet, F.; Jaubert, J.-N. High carbon dioxide solubilities in imidazolium-based ionic liquids and in poly (ethylene glycol) dimethyl ether. J. Phys. Chem. B 2010, 114, 12908-12913.

(55) Yim, J.-H.; Song, H. N.; Yoo, K.-P.; Lim, J. S. Measurement of $\mathrm{CO} 2$ solubility in ionic liquids: $[\mathrm{BMP}][\mathrm{Tf} 2 \mathrm{~N}]$ and $[\mathrm{BMP}][\mathrm{MeSO} 4]$ by measuring bubble-point pressure. J. Chem. Eng. Data 2011, 56, 1197-1203.

(56) Jalili, A. H.; Mehdizadeh, A.; Shokouhi, M.; Ahmadi, A. N.; Hosseini-Jenab, M.; Fateminassab, F. Solubility and diffusion of $\mathrm{CO} 2$ and $\mathrm{H} 2 \mathrm{~S}$ in the ionic liquid 1-ethyl-3-methylimidazolium ethylsulfate. J. Chem. Thermodyn. 2010, 42, 1298-1303.

(57) Ramdin, M.; Amplianitis, A.; Bazhenov, S.; Volkov, A.; Volkov, V.; Vlugt, T. J. H.; de Loos, T. W. Solubility of $\mathrm{CO} 2$ and $\mathrm{CH} 4$ in ionic liquids: ideal $\mathrm{CO} 2 / \mathrm{CH} 4$ selectivity. Ind. Eng. Chem. Res. 2014, 53, $15427-15435$.

(58) Almantariotis, D.; Stevanovic, S.; Fandino, O.; Pensado, A. S.; Padua, A. A. H.; Coxam, J.-Y.; Costa Gomes, M. Absorption of Carbon Dioxide, Nitrous Oxide, Ethane and Nitrogen by 1-Alkyl-3methylimidazolium ( $\mathrm{C} \mathrm{n} \mathrm{mim,} \mathrm{n}=2,4,6)$ Tris (pentafluoroethyl) trifluorophosphate Ionic Liquids (eFAP). J. Phys. Chem. B 2012, 116, $7728-7738$

(59) Morgan, D.; Ferguson, L.; Scovazzo, P. Diffusivities of gases in room-temperature ionic liquids: data and correlations obtained using a lag-time technique. Ind. Eng. Chem. Res. 2005, 44, 4815-4823.

(60) Aki, S. N. V. K.; Mellein, B. R.; Saurer, E. M.; Brennecke, J. F. High-pressure phase behavior of carbon dioxide with imidazoliumbased ionic liquids. J. Phys. Chem. B 2004, 108, 20355-20365.

(61) Anderson, J. L.; Dixon, J. K.; Brennecke, J. F. Solubility of CO2, $\mathrm{CH} 4, \mathrm{C} 2 \mathrm{H} 6, \mathrm{C} 2 \mathrm{H} 4, \mathrm{O} 2$, and $\mathrm{N} 2$ in 1-Hexyl-3-methylpyridinium Bis 
(trifluoromethylsulfonyl) imide: Comparison to Other Ionic Liquids. Acc. Chem. Res. 2007, 40, 1208-1216.

(62) Blanchard, L. A.; Gu, Z.; Brennecke, J. F. High-pressure phase behavior of ionic liquid/CO2 systems. J. Phys. Chem. B 2001, 105, $2437-2444$.

(63) Jacquemin, J.; Gomes, M. F. C.; Husson, P.; Majer, V. Solubility of carbon dioxide, ethane, methane, oxygen, nitrogen, hydrogen, argon, and carbon monoxide in 1-butyl-3-methylimidazolium tetrafluoroborate between temperatures $283 \mathrm{~K}$ and $343 \mathrm{~K}$ and at pressures close to atmospheric. J. Chem. Thermodyn. 2006, 38, 490502.

(64) Palgunadi, J.; Kang, J. E.; Nguyen, D. Q.; Kim, J. H.; Min, B. K.; Lee, S. D.; Kim, H.; Kim, H. S. Solubility of $\mathrm{CO} 2$ in dialkylimidazolium dialkylphosphate ionic liquids. Thermochim. Acta 2009, 494, 94-98.

(65) Zhao, Y.; Zhang, X.; Dong, H.; Zhen, Y.; Li, G.; Zeng, S.; Zhang, S. Solubilities of gases in novel alcamines ionic liquid 2-[2hydroxyethyl (methyl) amino] ethanol chloride. Fluid Phase Equilib. 2011, 302, 60-64.

(66) Manic, M. S.; Macedo, E. A.; Najdanovic-Visak, V. Trihexyl (tetradecyl) phosphonium bromide: Liquid density, surface tension and solubility of carbondioxide. Fluid Phase Equilib. 2012, 324, 8-12.

(67) Soriano, A. N.; Doma, B. T., Jr.; Li, M.-H. Solubility of carbon dioxide in 1-ethyl-3-methylimidazolium tetrafluoroborate. J. Chem. Eng. Data 2008, 53, 2550-2555.

(68) Lei, Z.; Yuan, J.; Zhu, J. Solubility of $\mathrm{CO} 2$ in propanone, 1ethyl-3-methylimidazolium tetrafluoroborate, and their mixtures. $J$. Chem. Eng. Data 2010, 55, 4190-4194.

(69) Lazzús, J. A. A group contribution method to predict the melting point of ionic liquids. Fluid Phase Equilib. 2012, 313, 1-6.

(70) Chen, Y.; Kontogeorgis, G. M.; Woodley, J. M. Group Contribution-based estimation method for properties of ionic liquids. Ind. Eng. Chem. Res. 2019, 58, 4277-4292.

(71) Zhao, Y.; Yang, J.; Qin, B.; Li, Y.; Sun, Y.; Su, S.; Xian, M. Biosynthesis of isoprene in Escherichia coli via methylerythritol phosphate (MEP) pathway. Appl. Microbiol. Biotechnol. 2011, 90, $1915-1922$.

(72) Liu, C.-L.; Bi, H.-R.; Bai, Z.; Fan, L.-H.; Tan, T.-W. Engineering and manipulation of a mevalonate pathway in Escherichia coli for isoprene production. Appl. Microbiol. Biotechnol. 2019, 103, 239-250.

(73) Tian, H.; Zada, B.; Singh, B. H.; Wang, C.; Kim, S.-W. Synthetic Biology Approaches for the Production of Isoprenoids in Escherichia coli. Curr. Dev. Biotechnol. Bioeng. 2019, 311-329.

(74) Anthony, J. R.; Anthony, L. C.; Nowroozi, F.; Kwon, G.; Newman, J. D.; Keasling, J. D. Optimization of the mevalonate-based isoprenoid biosynthetic pathway in Escherichia coli for production of the anti-malarial drug precursor amorpha-4, 11-diene. Metab. Eng. 2009, 11, 13-19.

(75) Huang, Y.; Dong, H.; Zhang, X.; Li, C.; Zhang, S. A new fragment contribution-corresponding states method for physicochemical properties prediction of ionic liquids. AIChE J. 2013, 59, 13481359.

(76) Wittig, R.; Lohmann, J.; Gmehling, J. Vapor- liquid equilibria by UNIFAC group contribution. 6. Revision and extension. Ind. Eng. Chem. Res. 2003, 42, 183-188.

(77) Cervin, M. A.; Chotani, G. K.; Feher, F. J.; La Duca, R.; McAuliffe, J. C.; Miasnikov, A.; Peres, C. M.; Puhala, A. S.; Sanford, K. J.; Valle, F. Compositions and Methods for Producing Isoprene. U.S. Patent US8,288,1482012. 